\title{
Regulation of erythropoietin production is related to proximal tubular function
}

\author{
KAI-UWE ECKARDT, ARMIN KURTZ, AND CHRISTIAN BAUER \\ Department of Physiology, University of Zürich, CH-8057 Zürich, Switzerland
}

EckardT, KaI-Uwe, Armin Kurtz, AND Christian BAUER. Regulation of erythropoietin production is related to proximal tubular function. Am. J. Physiol. 256 (Renal Fluid Electrolyte Physiol. 25): F942-F947, 1989._Regulation of renal erythropoietin (EPO) production is based on an intrarenal oxygen sensor. Whereas the sensitivity of this oxygen sensor to variations in renal oxygen supply is well established, the influence of changes in renal oxygen consumption has not yet been elucidated. Diuretic drugs, which inhibit active sodium reabsorption, reduce tubular oxygen consumption. We therefore investigated the effects of acetazolamide, furosemide, hydrochlorothiazide, and amiloride, known to preferentially inhibit sodium reabsorption at different segments of the nephron, on hypoxia-induced EPO formation in mice. Those drugs that are considered to act mainly in the loop of Henle, distal tubule, and collecting duct (furosemide, hydrochlorothiazide, and amiloride) did not impair EPO formation. Acetazolamide on the other hand, which is thought to act predominantly at the proximal tubular site, significantly reduced EPO formation in response to normobaric hypoxia $\left(8\right.$ and $\left.14 \% \mathrm{O}_{2}\right)$ and functional anemia $(0.1 \%$ carbon monoxide). This inhibitory effect of acetazolamide was dose dependent and correlated with the natriuresis induced. It appeared not to depend on the metabolic acidosis induced by the drug, since the simultaneous administration of sodium bicarbonate, which restored standard bicarbonate levels to normal, did not diminish the inhibitory effect of acetazolamide on EPO production. In conclusion the data suggest that the regulation of EPO production is likely to be related to proximal tubular function.

kidney; hypoxia; diuretics; acetazolamide; furosemide; hydrochlorothiazide; amiloride; renal oxygen consumption

REGULATION of renal erythropoietin (EPO) production is based on a sensing mechanism that detects changes in the oxygen content of blood (6). Although the precise cellular site of this "oxygen sensor" is yet unknown, strong evidence indicates that it is located in the kidney itself. Thus isolated perfused kidneys have been shown to release more EPO on lowering the oxygen tension of the perfusate $(5,9,15,26)$ and selective reduction of renal oxygen supply in normoxic animals is able to enhance EPO production $(10,22)$.

The oxygen-dependent parameter that is perceived by the oxygen sensor is likely to be influenced not only by renal oxygen supply but also, in an inverse fashion, by renal oxygen consumption. The predominant determinant of renal oxygen consumption is tubular sodium reabsorption $(3,13,17,24)$. However, a direct relationship between EPO production and tubular oxygen con- sumption has not yet been established. Recently it has been shown that the cells producing EPO are not part of the renal tubule itself, but are located in the renal interstitium $(14,16)$. The question arises therefore, whether or not the regulation of EPO production is at all related to tubular function. In addition, if such a relationship between tubular function and EPO production exists, it seems essential for the understanding of the renal oxygen sensor to define the part of the nephron involved in the regulation of EPO production.

To investigate this question, we used diuretic drugs with predominant sites of action at different segments of the nephron to inhibit sodium reabsorption and therewith reduce tubular oxygen consumption. We studied the effect of this intervention on the hypoxia-induced EPO response in mice. The influence of different diuretics on EPO production has to our knowledge so far only been investigated by Fisher et al. (8) in 1963. However, these investigators chose an entirely different approach, as they used cobalt as stimulus for EPO formation. Indirect evidence for a role of tubular work in the regulation of EPO production was previously provided by Miller and co-workers (19). They have demonstrated an inhibitory effect of acetazolamide on EPO production in humans exposed to simulated altitude. However, in their study a potential effect of acetazolamide on sodium reabsorption and renal oxygen consumption was not considered. The authors attributed the inhibitory effect of acetazolamide to prevention of the respiratory alkalosis normally occurring under hypoxia and an associated rightward shift of the oxygen dissociation curve, finally resulting in an increased peripheral tissue oxygenation.

Employing four different diuretics, our results show that furosemide, hydrochlorothiazide, and amiloride, which are considered to mainly effect sodium transport in the loop of Henle, the distal tubule, and collecting duct, respectively, do not impair the hypoxia-induced EPO production. On the other hand, acetazolamide that is thought to preferentially act at the proximal tubular site, significantly reduced EPO formation in close correlation to the natriuresis induced and independent from changes in systemic acid base status.

\section{MATERIALS AND METHODS}

Male Institute of Cancer Research (ICR) strain mice (body wt 25-32 g) were used in this study.

Hypoxic stimulation of EPO production. Normobaric arterial hypoxia or functional anemia caused by carbon 
monoxide inhalation were used as stimuli for EPO formation. To this end, animals were exposed to an atmosphere low in oxygen $\left(8\right.$ or $\left.14 \% \mathrm{O}_{2}\right)$ or normal air with added carbon monoxide $(0.1 \% \mathrm{CO})$, using chambers that were gassed with mixtures of normal atmospheric air and nitrogen or carbon monoxide. Animals treated with diuretics and their respective controls were simultaneously exposed to the hypoxic stimuli for $3 \mathrm{~h}$.

Within $15 \mathrm{~min}$ after the end of hypoxic exposure animals were bled from the retro-orbital sinus under ether anesthesia for determination of serum EPO levels (see below).

Experiments with diuretics. To investigate the effect of inhibition of sodium absorption at different nephron segments on EPO production, the following site-predominant diuretics $(12,21)$ were used: 1$)$ acetazolamide (Diamox, Lederle Parenterals, Carolina, PR; proximal tubule), 2) furosemide (Lasix, Hoechst, Frankfurt, FRG; loop of Henle), 3) hydrochlorothiazide (Sigma, St. Louis, MO; early distal tubule), and 4) amiloride (Sigma; late distal tubule and collecting duct). Solutions for application were prepared as follows: acetazolamide dissolved in $0.9 \% \mathrm{NaCl}$, furosemide diluted with $0.9 \% \mathrm{NaCl}$, hydrochlorothiazide dissolved in $0.1 \mathrm{M} \mathrm{NaOH}$ and the solution then adjusted to $\mathrm{pH} 6-7$ and amiloride dissolved in distilled water. A total of $200 \mu \mathrm{l}$ of these solutions containing $25,100,200$, or $500 \mathrm{mg} / \mathrm{kg}$ body wt acetazolamide, $20 \mathrm{mg} / \mathrm{kg}$ body wt furosemide, $6 \mathrm{mg} / \mathrm{kg}$ body wt hydrochlorothiazide, or $2 \mathrm{mg} / \mathrm{kg}$ body wt amiloride, respectively, were injected into mice $50 \%$ intravenously into a tail vein and $50 \%$ intraperitoneally immediately before hypoxic exposure. Control animals were injected with $200 \mu \mathrm{l}$ of the vehicle only. To quantitate the diuretic effect of these drugs, urine voided by five animals each within $3 \mathrm{~h}$ after application of diuretics was collected in metabolic cages and analyzed for sodium content by flame photometry (Corning Flame Photometer $410 \mathrm{C}$, Corning Medical, Medfield, MA).

Experiments with sodium bicarbonate. To compensate for the metabolic acidosis induced by acetazolamide, animals in a separate set of experiments were injected simultaneously with acetazolamide $(500 \mathrm{mg} / \mathrm{kg}$ body wt) and sodium bicarbonate at a dose of $20 \mathrm{mmol} / \mathrm{kg} \mathrm{(1} \mathrm{M}$ solution, injected $50 \%$ intraperitoneally and $50 \%$ subcutaneously). Additional controls were treated with the same dose of sodium bicarbonate only.

Prior to and during all experiments animals had free access to tap water.

Determination of EPO. EPO was measured by radioimmunoassay (RIA) as described (4), using a rabbit antiserum raised against recombinant human EPO and iodinated recombinant EPO (Amersham International, Amersham, UK) as tracer. A mouse serum pool enriched in EPO, prepared by exposing animals to normobaric hypoxia for $18 \mathrm{~h}$, was calibrated against human EPO (2nd International Reference Preparation, World Health Organization) in the polycythemic mouse bioassay (4) and used as standard in the RIA (Fig. 1).

Determination of standard bicarbonate concentrations. Animals were anesthetized with $500 \mathrm{mg} / \mathrm{kg}$ body wt 5ethyl-5-(1'-methylpropyl)-2-thiobarbituric acid (Inactin, Byk-Gulden, Constance, FRG) injected intraperitoneally in a concentration of $100 \mathrm{mg} / \mathrm{ml}$. Immediately after onset of anesthesia they were bled from the retro-orbital sinus into heparinized glass capillary tubes that were then instantly transferred to a computerized blood gas analyzer (IL 1304, Instrumentation Laboratory, Lexington, MA).

Statistics. Levels of significance were calculated by use of Student's $t$ test. $P<0.05$ was considered significant.

\section{RESULTS}

Kinetics of hypoxia-induced EPO response. Figure 2 shows the kinetics of serum EPO levels in response to normobaric hypoxia $\left(7 \% \mathrm{O}_{2}\right)$ and functional anemia induced by carbon monoxide inhalation $(0.1 \% \mathrm{CO})$. Consistent with previous investigations $(2,20)$ serum EPO levels began to rise 1-2 $\mathrm{h}$ after the onset of the hypoxic stimulus. Independent of the degree of stimulation a linear increase of serum EPO levels was observed after 3 $\mathrm{h}$ of hypoxia and this time point was therefore selected for further experiments.

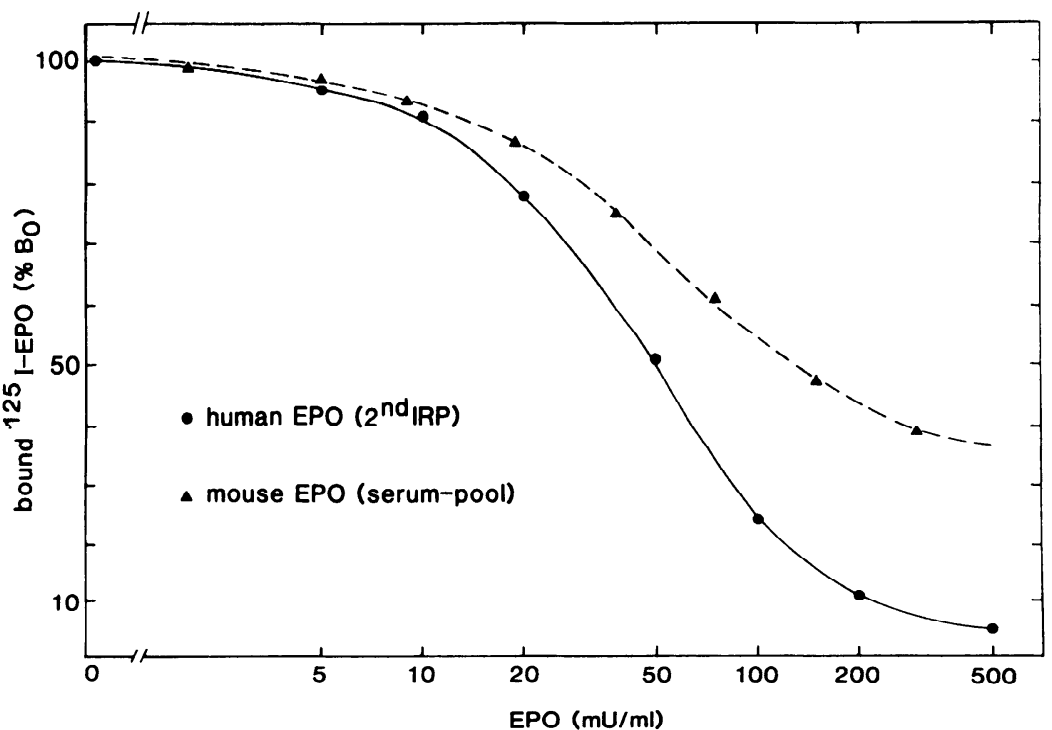

FIG. 1. Standard curves of the erythropoietin radioimmunoassay (EPO RIA), demonstrating cross-reactivity of mouse EPO with antiserum derived against recombinant human EPO. Total amount of antibody-precipitable ${ }^{125}$ I-labeled EPO in absence of unlabeled EPO $\left(\mathrm{B}_{0}\right)$ was on average $45 \%$ of the radioactivity added. 


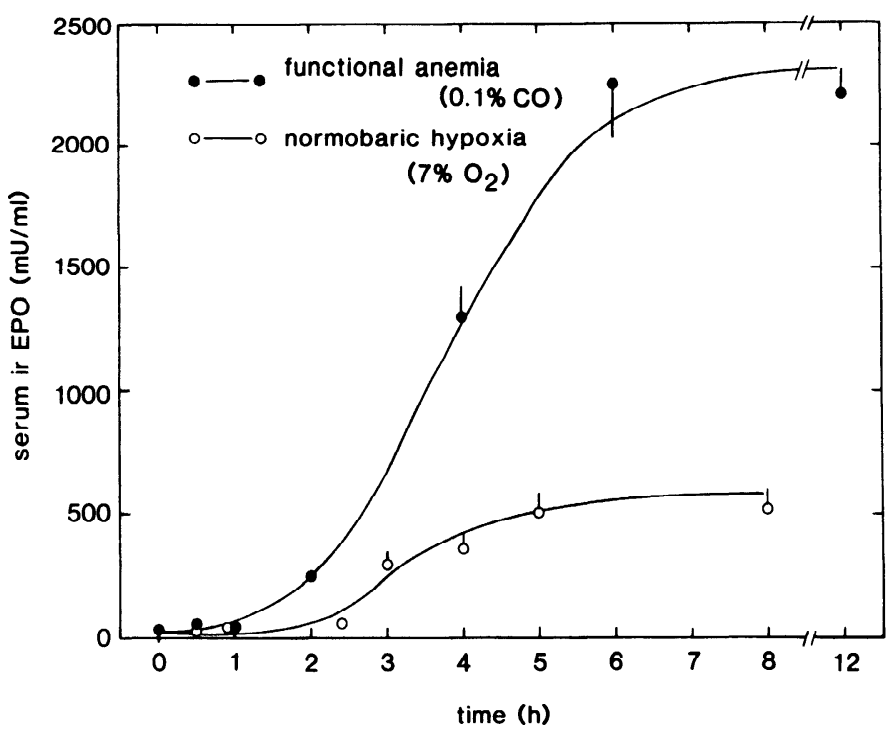

FIG. 2. Time-dependent increases of serum erythropoietin (EPO) levels in response to normobaric hypoxia and carbon monoxide inhalation (mean $\pm \mathrm{SE}, n=5$ ).

TABLE 1. Effect of diuretics on urine and sodium excretion

\begin{tabular}{lccc}
\hline \hline & $\begin{array}{c}\text { Urine Flow, } \\
\mathrm{ml} / 3 \mathrm{~h}\end{array}$ & $\begin{array}{c}\text { Sodium } \\
\text { Concentration, } \\
\text { mmol/l }\end{array}$ & $\begin{array}{c}\text { Sodium } \\
\text { Excretion, } \\
\mu \mathrm{mol} / 3 \mathrm{~h}\end{array}$ \\
\hline Controls & 0.16 & 57 & 9 \\
$\begin{array}{c}\text { Acetazolamide } \\
\quad(500 \mathrm{mg} / \mathrm{kg})\end{array}$ & 0.85 & 250 & 213 \\
$\begin{array}{l}\text { Furosemide }(20 \mathrm{mg} / \mathrm{kg}) \\
\text { Hydrochlorothiazide }\end{array}$ & 1.50 & 139 & 209 \\
$\quad(6 \mathrm{mg} / \mathrm{kg})$ & 0.50 & 98 & 49 \\
Amiloride $(2 \mathrm{mg} / \mathrm{kg})$ & 0.40 & 121 & 48 \\
\hline
\end{tabular}

Urine was collected from five animals under each condition. Data represent the average excretion of one animal within $3 \mathrm{~h}$.

Effect of diuretics on sodium excretion and urine volume. Acetazolamide, furosemide, hydrochlorothiazide, and amiloride were used to inhibit sodium reabsorption predominantly site specific in the proximal tubule, the thick ascending limb of the loop of Henle, the early distal tubule, and the late distal tubule and collecting duct, respectively. To assess the degree of inhibition of sodium reabsorption, the effects of the diuretics on urine volume and sodium excretion were measured and the results are given in Table 1. All four drugs led to significant diuresis and natriuresis. To assess a possible underestimation of the effectiveness of acetazolamide caused by compensatory sodium reabsorption in the more distal parts of the nephron, the natriuretic effect of a low dose $(25 \mathrm{mg} / \mathrm{kg})$ of acetazolamide was also tested in the presence of furosemide and hydrochlorothiazide. However, under these conditions the acetazolamide-induced increase in natriuresis was not different from the natriuresis brought about by acetazolamide alone ( $41 \mu \mathrm{mol}$ vs. $40 \mu \mathrm{mol} \mathrm{Na}$ per animal within $3 \mathrm{~h}$ ).

Effect of diuretics on EPO production. To test any direct stimulatory effect of the diuretics on EPO production, which might have compensated a possible reduction of hypoxia-induced EPO formation, EPO levels were measured in normoxic animals after application of di- uretics for $3 \mathrm{~h}$. With acetazolamide ( 25 or $500 \mathrm{mg} / \mathrm{kg}$ ), hydrochlorothiazide and amiloride EPO levels did not change significantly (data not shown), whereas with furosemide we observed an increase from $29.5 \pm 3$ to 55.2 $\pm 12 \mathrm{mU} / \mathrm{ml}$ (mean $\pm \mathrm{SE}, n=10 ; P<0.005$ ).

To study the effect of diuretics on hypoxia-induced EPO formation, hypoxic stimuli of three different degrees, including two degrees of normobaric arterial hypoxia as well as carbon monoxide inhalation were used. The results obtained with carbon monoxide inhalation $(0.1 \%)$ are shown in Fig. 3. With furosemide, hydrochlorothiazide, and amiloride we found no alteration of the hypoxia-induced EPO response compared with control animals injected with the vehicle only. Also the combined application of furosemide and hydrochlorothiazide did not influence EPO formation. With acetazolamide (500 $\mathrm{mg} / \mathrm{kg}$ ), however, there was a significant reduction of the EPO response $(P<0.001)$.

A similar inhibitory effect of acetazolamide on EPO production was observed in response to both degrees of arterial hypoxia $\left(8 \% \mathrm{O}_{2}\right.$ and $\left.14 \% \mathrm{O}_{2}\right)$. (Fig. 4, left). In contrast, furosemide and hydrochlorothiazide, either alone or in combination, and amiloride did not reduce the EPO response (Table 2). With furosemide there was even a slight, but significant increase in response to both stimuli.

Figure 4 (right) shows that the inhibitory effect of acetazolamide on EPO production in response to normobaric hypoxia $\left(8 \% \mathrm{O}_{2}\right)$ was dose dependent; whereas 25 and $100 \mathrm{mg} / \mathrm{kg}$ did not change EPO production significantly, EPO levels were significantly reduced after administration of 200 and $500 \mathrm{mg} / \mathrm{kg}(P<0.025$ and $P$ $<0.001$, respectively). In contrast the effect of acetazolamide on acid-base status of the animals was not dose dependent over the same range of concentrations, as demonstrated in Fig. 5, top. Both 25 and $500 \mathrm{mg} / \mathrm{kg}$ body wt led to a significant reduction of sodium bicarbonate concentrations $(P<0.01)$ that was, however, not differ-

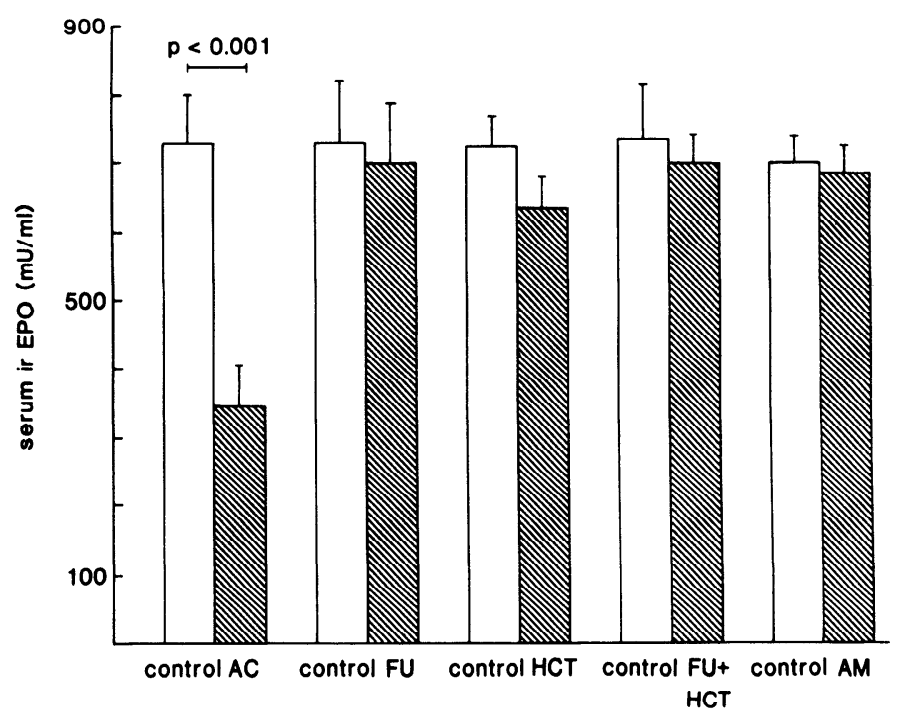

FIG. 3. Serum erythropoietin (EPO) levels after $3 \mathrm{~h}$ exposure to carbon monoxide $(0.1 \%)$ in animals treated with acetazolamide (AC), furosemide (FU), and hydrochlorothiazide (HCT), either alone or in combination (FU+HCT), and amiloride (AM). Respective controls, injected with vehicle only, were simultaneously exposed to hypoxia (means $\pm \mathrm{SE}, n=5-12$ ). 


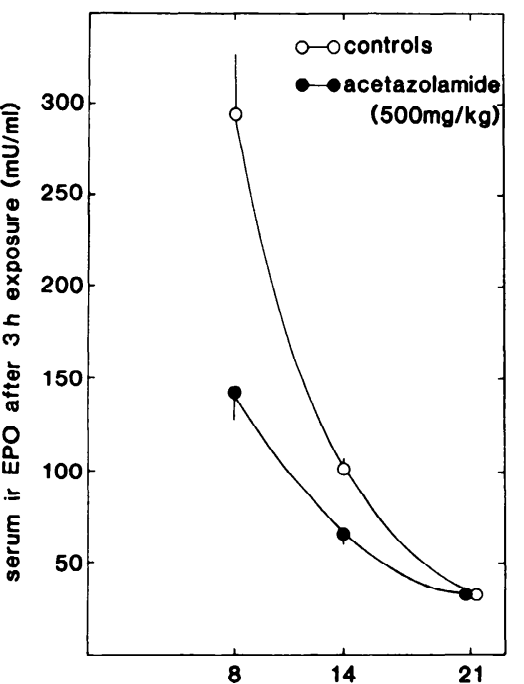

oxygen content of inspiratory gas (\%)

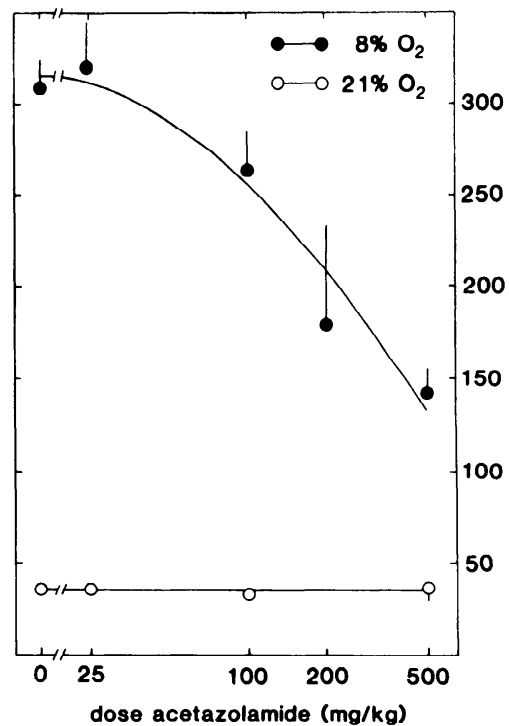

FIG. 4. Effect of acetazolamide $(500 \mathrm{mg} / \mathrm{kg})$ on erythropoietin (EPO) production in response to different degrees of normobaric arterial hypoxia (left) and effect of different doses of acetazolamide on EPO production in response to normobaric arterial hypoxia $\left(8 \% \mathrm{O}_{2}\right)$ (right) (means $\pm \mathrm{SE}, n=10-20$ ). EPO levels under acetazolamide were significantly different from untreated controls with a dose of $500 \mathrm{mg} / \mathrm{kg}$ at $8 \%(P<0.001)$ and $14 \% \mathrm{O}_{2}(P<$ $0.001)$ and with a dose of $200 \mathrm{mg} / \mathrm{kg}$ at $8 \% \mathrm{O}_{2}(P<0.025)$.
TABLE 2. Serum EPO levels $(\mathrm{mU} / \mathrm{ml}$ ) after $3 \mathrm{~h}$ exposure to normobaric arterial hypoxia in control animals and animals treated with diuretics

\begin{tabular}{lccccc}
\hline \hline & \multicolumn{2}{c}{$14 \% \mathrm{O}_{2}$} & & \multicolumn{2}{c}{$8 \% \mathrm{O}_{2}$} \\
\cline { 2 - 3 } \cline { 5 - 6 } & Control & Drug & & Control & Drug \\
\hline Furosemide $(20 \mathrm{mg} / \mathrm{kg})$ & $98 \pm 19$ & $121 \pm 13^{*}$ & & $265 \pm 97$ & $317 \pm 23^{*}$ \\
& $(10)$ & $(5)$ & $(28)$ & $(30)$ \\
Hydrochlorothiazide & $104 \pm 29$ & $97 \pm 30$ & & $314 \pm 60$ & $300 \pm 27$ \\
$\quad(6 \mathrm{mg} / \mathrm{kg})$ & $(5)$ & $(5)$ & $(5)$ & $(5)$ \\
Furosemide $(20 \mathrm{mg} / \mathrm{kg})+$ & $91 \pm 18$ & $91 \pm 16$ & & $275 \pm 27$ & $283 \pm 27$ \\
$\quad$ hydrochlorothiazide & $(10)$ & $(10)$ & & $(20)$ & $(20)$ \\
$\quad(6 \mathrm{mg} / \mathrm{kg})$ & & & & \\
Amiloride $(2 \mathrm{mg} / \mathrm{kg})$ & $104 \pm 29$ & $111 \pm 58$ & $286 \pm 40$ & $280 \pm 28$ \\
& $(5)$ & $(5)$ & & $(15)$ & $(15)$ \\
\hline
\end{tabular}

Values are means $\pm \mathrm{SE}$; values in parentheses are no. of animals. EPO, erythropoietin. ${ }^{*} P<0.05$.

ent between the two doses. Furthermore, simultaneous application of sodium bicarbonate together with acetazolamide, which restored standard bicarbonate levels to at least normal concentrations (Fig. 5, top), did not diminish the inhibitory effect of acetazolamide on EPO production in response to hypoxia $\left(8 \% \mathrm{O}_{2}\right)$ (Fig. 5, bottom). Sodium bicarbonate per se did not significantly alter the hypoxia-induced EPO formation (Fig. 5, bottom). Figure 6 demonstrates that the inhibitory effect of acetazolamide on EPO production paralleled the natriuresis brought about with the different doses of the drug.

\section{DISCUSSION}

This study was aimed at investigating the effect of inhibition of tubular sodium reabsorption in different parts of the nephron on the hypoxia-induced renal EPO formation. To this end we used diuretic drugs that are known to block sodium reabsorption preferentially in the proximal tubule (acetazolamide), the thick ascending limb of the loop of Henle (furosemide), the early distal tubule (hydrochlorothiazide), and the late distal tubule and collecting duct (amiloride) $(12,21)$. We explicitly assume that an inhibition of sodium reabsorption is associated with a decrease in tubular oxygen consump-
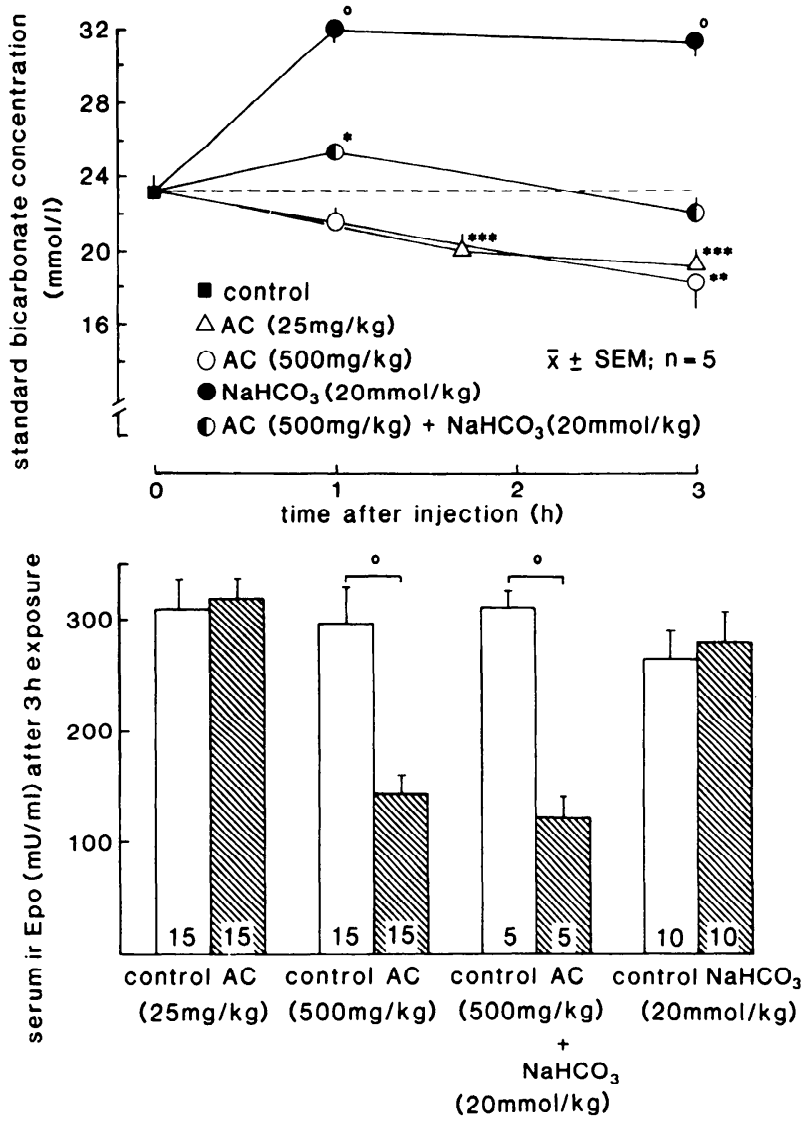

FIG. 5. Effect of acetazolamide (AC; 25 or $500 \mathrm{mg} / \mathrm{kg}$ ), sodium bicarbonate $\left(\mathrm{NaHCO}_{3} ; 20 \mathrm{mmol} / \mathrm{kg}\right)$ and combined application of $\mathrm{AC}$ and $\mathrm{NaHCO}_{3}(20 \mathrm{mmol} / \mathrm{kg})$ on standard bicarbonate concentrations (top) and erythropoietin (EPO) formation in response to $8 \% \mathrm{O}_{2}$ (bottom). ${ }^{*} P<0.025$; $^{* *} P<0.01$; ${ }^{* * *} P<0.005$; $^{\circ} P<0.001$ vs. controls.

tion. This assumption is supported by a number of experiments in which a positive and linear relationship was established between the amount of sodium reabsorbed and renal oxygen consumption $(3,13,17,24)$.

Interpretation of the effect of the diuretics used in the present study on EPO formation requires an estimate of the efficacy with which sodium reabsorption was blocked 


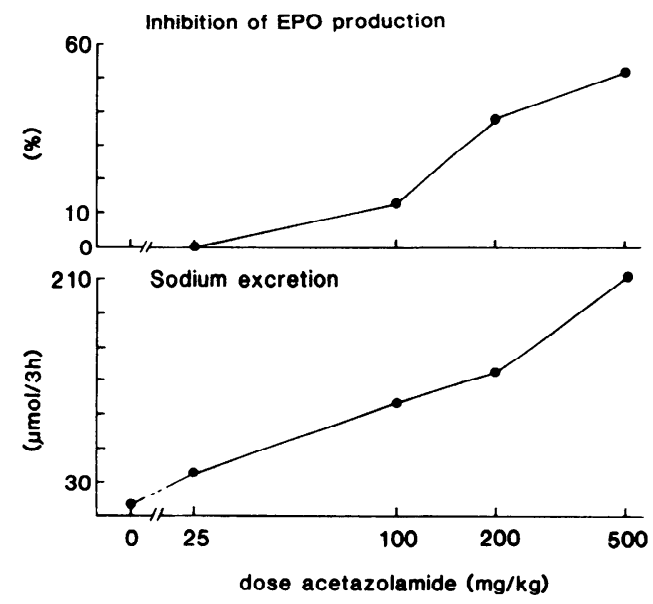

FIG. 6. Dose-response relationship of acetazolamide with respect to inhibition of erythropoietin (EPO) production and urinary sodium excretion.

at the respective segments of the nephron. Such an estimate can be made on the basis of the data on sodium excretion in controls and in animals receiving diuretics (Table 1). Assuming that sodium excretion of control animals corresponds to $1 \%$ of their filtered sodium load, an approximate calculation of fractional sodium excretion under the different diuretics can be computed by relating the absolute sodium excretion of animals with diuretic treatment to that of controls (Table 3, top half). A comparison of these figures with the fraction of sodium normally reabsorbed at the different parts of the nephron $(11,21)$ (Table 3, bottom half) reveals that with amiloride, hydrochlorothiazide, and furosemide in the doses used, sodium reabsorption was intensively blocked in the collecting duct, distal tubule, and thick ascending limb of the loop of Henle.

Nevertheless, the EPO response to mild and severe hypoxia was not reduced under each of these three diuretics (Table 2, Fig. 3). Also the combined application of furosemide and hydrochlorothiazide did not blunt the EPO response, thus excluding the possibility of masking a potential effect of furosemide on EPO production by a compensatory increase of distal tubular reabsorption rate. How furosemide led to a slight increase of basal as well as stimulated EPO levels in response to arterial hypoxia (Table 2) cannot be explained on the basis of the present investigation. However, furosemide is known to increase renal prostaglandin formation $(1,26)$, and prostaglandins have been shown to stimulate EPO production (7).

In contrast to the results obtained with diuretics acting in the loop of Henle and more distal parts of the nephron we found a significant reduction of hypoxia-induced EPO formation after administration of acetazolamide, a diuretic that is considered to act predominantly at the proximal tubular site $(12,21)$, using a dose of 200 or 500 $\mathrm{mg} / \mathrm{kg}$ (Figs. 3 and 4). It should be noted that doses of acetazolamide given to humans are severalfold lower on a dose per kilogram body weight basis. However, natriuresis achieved with the low doses used in clinical routine usually does not exceed $5 \%$ of the filtered sodium load (12). In contrast, with the dosage of $500 \mathrm{mg}$ acetazolamide $/ \mathrm{kg}$, up to which a linear log dose-response relationship has previously been established for the drug (18), fractional sodium excretion corresponded to approximately one-third of normal proximal tubular sodium reabsorption (Table 3). Two established effects of acetazolamide are likely to reduce the oxygen demand of the proximal tubule. First, the drug directly interferes with reabsorptive function by inhibiting carbonic anhydrase and second, it diminishes reabsorption rate indirectly by reducing the filtered solute load via activation of the tubuloglomerular feedback system $(12,21)$. At the same time urinary bicarbonate loss leads to a reduction in plasma bicarbonate concentrations. Miller and coworkers (19), who previously demonstrated an inhibitory effect of acetazolamide on EPO production in humans, attributed this effect to changes in the acid base status. The authors concluded that acetazolamide treatment prevented the respiratory alkalosis, normally occurring under hypoxic conditions, and thereby prevented a leftward shift in the oxygen dissociation curve, finally resulting in an increased peripheral tissue oxygenation. These investigators did not consider a potential effect of acetazolamide on sodium reabsorption. However, it has been demonstrated that a comparable dose of acetazolamide administered to humans causes a $30 \%$ rise in lithium clearance (23), thus indicating a considerable inhibition of proximal tubular sodium reabsorption. To further distinguish the possible mechanism by which the reduction in EPO response could have been mediated in our experiments, we intended to compensate for the metabolic acidosis, but not the natriuretic effect of the drug, by simultaneous treatment with acetazolamide and high doses of sodium bicarbonate. This regime resulted in normal or even slightly enhanced standard bicarbonate concentrations (Fig. 5, top). Nevertheless, the inhibitory effect of acetazolamide was not diminished by the simultaneous application of sodium bicarbonate (Fig. 5, bottom). Furthermore, the metabolic acidosis with low

TABLE 3. Fractional sodium excretion under diuretics and normal sodium reabsorption at respective site of diuretic action

\begin{tabular}{|c|c|c|c|c|}
\hline & $\begin{array}{l}\text { Acetazolamide, } \\
500 \mathrm{mg} / \mathrm{kg}\end{array}$ & $\begin{array}{l}\text { Furosemide, } \\
20 \mathrm{mg} / \mathrm{kg}\end{array}$ & $\begin{array}{l}\text { Hydrochlorothiazide, } \\
\qquad 6 \mathrm{mg} / \mathrm{kg}\end{array}$ & $\begin{array}{l}\text { Amiloride, } \\
2 \mathrm{mg} / \mathrm{kg}\end{array}$ \\
\hline $\begin{array}{l}\text { Estimate of fractional sodium } \\
\text { excretion }\end{array}$ & $24 \%$ & $23 \%$ & $5 \%$ & $5 \%$ \\
\hline $\begin{array}{l}\text { Normal sodium reabsorption at } \\
\text { respective site of diuretic action }\end{array}$ & $\begin{array}{c}50-60 \% \\
\text { (proximal tubule) }\end{array}$ & $\begin{array}{c}25-40 \% \\
\text { (loop of Henle) }\end{array}$ & $\begin{array}{c}8-10 \% \\
\text { (distal tubule) }\end{array}$ & $\begin{array}{c}1-2 \% \\
\text { (collecting duct) }\end{array}$ \\
\hline
\end{tabular}

Fractional sodium excretions under diuretics were calculated from the absolute values of sodium excretion (Table 1), assuming that in animals not treated with diuretics (controls in Table 1) fractional sodium excretion corresponded to $1 \%$ of the filtered load. Values for normal sodium reabsorption at respective site of diuretic action were taken from Refs. 11 and 21. 
doses of acetazolamide, which were ineffective with regard to EPO production, was not different from that at high doses, which significantly reduced EPO formation (Fig. 5, top), also indicating that both phenomena did not depend on each other. Although these findings suggest that the effect of acetazolamide on EPO formation was not mediated by systemic acidosis, we cannot definitely rule out a local acidosis at the proximal tubular site or a side effect of the drug on the EPO-producing cells. Presently, however, it is not possible to investigate a direct effect on the EPO-producing cells, since they have not yet been identified unequivocally. On the other hand, the inhibitory effect of acetazolamide on EPO formation strictly paralleled the natriuresis induced (Fig. 6 ) and it seems reasonable therefore to assume that the reduction of EPO formation is most likely related to a direct effect on the proximal tubule.

Recently Lacombe et al. (16) and Koury et al. (14) demonstrated the existence of messenger RNA for EPO in peritubular cells in the renal cortex and to a lesser extent in the outer medulla by using in situ hybridization. This location of the EPO-producing cells fits with a possible involvement of the proximal tubule in the regulation of EPO production, as inferred from the present study. It is not known at present whether the EPOproducing cells themselves are sensitive to hypoxia. In this case the function of the proximal tubule would be to lower the oxygen tension in the surrounding renal interstitium. Alternatively the proximal tubule could also generate a biochemical signal that stimulates EPO formation in the EPO-producing cells being located in its immediate vicinity.

We thank Prof. H. Murer and Prof. R. Greger for helpful discussions. The technical assistance of U. Bolliger, I. Grand, and W. Gehret, who did the artwork, is gratefully acknowledged.

The antiserum used in the radioimmunoassay for erythropoietin was a generous gift from Dr. P. Hirth, Boehringer Mannheim.

This study was supported by the Swiss National Science Foundation (grant 3023-084) and the Hartmann Müller Stiftung für Medizinische Forschung. K.-U. Eckardt was supported by a fellowship from the German Research Foundation.

Portions of these results were presented at the spring meeting of the British and German Physiological Society, Würzburg, March 1988, and published in abstract form (Pfluegers Arch. 411: R 92, 1988).

Address for reprint requests: K.-U. Eckardt, Physiologisches Institut, Universität Zürich, Winterthurerstrasse 190, CH 8057 Zürich, Switzerland.

Received 23 June 1988; accepted in final form 6 February 1989.

\section{REFERENCES}

1. Abe, K., M. Yasuima, L. Cheiba, N. Irokawa, P. Ipo, and K. YoshinaGa. Effect of furosemide on urinary excretion of prostaglandin $\mathrm{E}$ in normal volunteers and patients with essential hypertension. Prostaglandins 14: 513-521, 1977.

2. Clemons, G. C., D. DeMannicor, S. L. Fitzsimmons, and J. F GARCIA. Immunoreactive erythropoietin studies in hypoxic rats and the role of the salivary glands. Exp. Hematol. 15: 18-23, 1987.

3. Deetjen, P., AND K. Kramer. Die Abhängigkeit des $\mathrm{O}_{2}$-Verbrauches der Niere von der Na-Rückresorption. Pfluegers Arch. 273: 636-650, 1961.
4. Eckardt, K.-U., A. Kurtz, P. Hirth, P. Scigalla, L. WieczoREK, AND C. BAUER. Evaluation of the stability of human erythropoietin in samples for radioimmunoassay. Klin. Wochenschr. 66: 241-245, 1988.

5. ERSLEV, A. J. In vitro production of erythropoietin by kidneys perfused with a serum-free solution. Blood 44: 77-85, 1974

6. Erslev, A. J., J. Caro, and A. BesaraB. Why the kidney? Nephron 41: 213-216, 1985.

7. FISHER, J. W. Prostaglandins and kidney erythropoietin production. Nephron 25: 53-56, 1980.

8. Fisher, J. W., D. B. KNight, and C. Couch. The influence of several diuretic drugs on erythropoietin formation. J. Pharmacol. Exp. Ther. 141: 113-121, 1963.

9. Fisher, J. W., AND J. W. LANGSTON. Effects of testosterone, cobalt and hypoxia on erythropoietin production in the isolated perfused dog kidney. Ann. NY Acad. Sci. 149: 75-87, 1968.

10. FISHER, J. W., AND A. I. SAMUELS. Relationship between renal blood flow and erythropoietin production in dogs. Proc. Soc. Exp. Biol. Med. 125: 482-485, 1967.

11. GIEBISCH, G., AND E. E. WindHAGER. Electrolyte transport across renal tubular membranes. In: Handbook of Physiology. Renal Physiology. Washington, DC: Am. Physiol. Soc., 1973, sect. 8, p. 315376.

12. GoldBerg, T. The renal physiology of diuretics. In: Handbook of Physiology. Renal Physiology. Washington, DC: Am. Physiol. Soc., 1973 , sect. 8, p. 1003-1031.

13. KIIL, F., K. AUKLAND, AND H. E. REFSUM. Renal sodium transport and oxygen consumption. Am. J. Physiol. 201: 511-516, 1961.

14. Koury, S. T., M. C. Bondurant, AND M. J. Koury. Localization of erythropoietin synthesizing cells in murine kidneys by in situ hybridization. Blood 71: 524-527, 1988.

15. Kuratowska, Z., B. Lewartowski, And E. Michalak. Studies on the production of erythropoietin by isolated perfused organs. Blood 18: 527-534, 1961.

16. Lacombe, C., J.-L. Da Silva, P. Bruneval, J.-G. Fournier, F. Wendling, N. Casadevall, J.-P. Camilleri, J. Bariety, B. VARET, AND P. TAMBourin. Peritubular cells are the site of erythropoietin synthesis in the murine hypoxic kidney. J. Clin. Invest. 81: 620-623, 1988.

17. LASSEN, N. A., O. MunCK, AND J. H. Thaysen. Oxygen consumption and sodium reabsorption in the kidney. Acta Physiol. Scand. 51: 371-384, 1961.

18. Mathisen, O., H. HoldaAs, AND F. Kill. Re-examination of the dose-response relationship for the renal effect of acetazolamide. Scand. J. Clin. Lab. Invest. 39: 297-301, 1979.

19. Miller, M. E., M. Rörth, H. H. Parving, D. Howard, I. Reddington, C. R. Valeri, and F. Stohlman. pH effect on erythropoietin response to hypoxia. N. Engl. J. Med. 288: 706-710, 1973.

20. Schooley, J. C., AND L. J. Mahlmann. Evidence for the de novo synthesis of erythropoietin in hypoxic rats. Blood 40: 662-670, 1972.

21. Suki, W. N., B. J. Stinebaugh, J. P. Frommer, and G. EkNOYAN. Physiology of diuretic action. In: The Kidney: Physiology and Pathophysiology, edited by D. W. Seldin and G. Giebisch. New York: Raven, 1985, p. 2127-2162.

22. TakakU, F., K. Hirashima, and K. NaKaO. Studies on the mechanism of erythropoietin production. I. Effect of unilateral constriction of the renal artery. J. Lab. Clin. Med. 59: 815-820, 1962.

23. Thomsen, K., AND M. Schou. Renal lithium excretion in man. Am. J. Physiol. 215: 823-827, 1968.

24. Thurau, $\mathrm{K}$. Renal $\mathrm{Na}$ reabsorption and $\mathrm{O}_{2}$ uptake in dogs during hypoxia and hydrochlorothiazide infusion. Proc. Soc. Exp. Biol. Med. 106: 714-717, 1961.

25. Wright, J. T., C. N. CoRder, AND R. TAYlor. Studies on rat kidney 15-hydroxyprostaglandin dehydrogenase. Biochem. Pharmacol. 25: 1669-1673, 1976.

26. Zangheri, E. O., H. Campana, F. Ponce, J. C. Silva, F. O. Fernandez, AND J. R. Suarez. Production of erythropoietin by hypoxic perfusion of the isolated kidney of the dog. Nature Lond. 199: 572-573, 1 \$3 